\title{
Real-Time Intelligent Parking Entrance Management
}

\author{
Sofia Belkhala ${ }^{1}$, Siham Benhadou ${ }^{2}$, Hicham Medromi ${ }^{3}$ \\ Research Foundation for Development and Innovation in Science and Engineering \\ Engineering research laboratory (LRI), System Architecture Team (EAS) \\ National and high school of electricity and mechanic (ENSEM) Hassan II University, Casablanca, Morocco 1, 2,3
}

\begin{abstract}
To help improve the situation of urban transport in the city of Casablanca, we have studied and set up a smart parking system. In this paper, we evaluate the management of the parking entrance utilising artificial intelligence. In addition, we want to establish the limits of our solution and its ability to respond to different requests in real time.
\end{abstract}

Keywords-Urban mobility; smart parking; IoT; artificial intelligence; agent; multi agent system; queuing theory

\section{INTRODUCTION}

The world today has become a major project for the city of tomorrow, visions led by investors, idea carriers, and the governance of the city, whose objectives are the modernization of cities while exploiting the emergence of technology in everyday life through connected objects. According to [1], a large part of our life is based on a virtual world, where we have an interconnection between services, products, infrastructure and citizens. This interconnection was made possible thanks to the Internet, today we have what is called: Internet of Things IoT, Internet of People IoP, Internet of energy IoE, and Internet of service IoS.

The emergence of technology is seen as a winning card to solve mobility problems that will contribute to the development of an intelligent city, providing these citizens with an efficient and sustainable transport network. Indeed, the car fleet has grown in recent years, this growth was not accompanied by modernization or improvement of infrastructures. In addition, the starting point and arrival point of a car is the parking, yet there are not enough of them in cities. This lack of parking has caused several problems:

- Unregulated rates

- Air pollution: due to $\mathrm{CO} 2$ emissions

- Congestion due to drivers looking for parking spaces

- Waste of time

As has been said, current technologies (Iot, IoP) will be the right choice for efficient, sustainable systems capable of making decisions in real-time. In this perspective, different solutions with different approaches were proposed, either for the collection of information on the Internet of Things, crowdsourcing, predictions for a parking space () or the services offered.

In order to have systems with the above-mentioned characters, the use of multi-agent systems MAS has proven necessary given their ability to operate in distributed environments, with real-time decision-making.
In the state of the art, there are works that have used multiagent systems to address different parking issues, [2] have used a MAS-based simulation environment to analyze the behavior of motorists looking for parking spaces in the urban environment. Author in [3] made between a Machine to Machine based architecture using MAS for the governance of the solution, according to them the use of MAS will allow them to work under complex conditions in distributed environments.

Author in [4] modeled the driver by an agent who has the behavior to drive, look for a parking space, parking and departure. In addition, what they have deployed includes reactions to different scenarios such as price variance, or lack of places. Authors in [5] established a system of negotiation and guidance based on agents who cooperate and coordinate with each other to negotiate parking prices and calculate the shortest route according to the driver's requirements.

On the other hand, researchers from Tunis [6] have been working on reducing the search time for parking spaces by a multi-agent approach to ensure coordination between drivers and the parking network in the city.

Our team works on a closed, indoor car park offering different services to its users, to ensure a good service, it is necessary to ensure that the time to be served must be minimal therefore the system must be able to manage the inputs/outputs with the different conditions at the time $t$ and deliver real-time responses. Indeed, according to Queue city: Authority and trust in the waiting line, queues have an effect on the emotional geography of the city of boredom, relaxation or even pain hope or rage and existential anxiety in relation to the order of queues and disorder.

In this paper, we will look at what is happening at the entrance, coordination between agents, decision-making and finally a study of the parameters of the queue in the case of our parking. After defining the multi-agent systems, we will introduce the agents responsible for input management, then we will move on to defining the parameters of the queue and then we end with a conclusion.

\section{PRoposed System}

\section{A. Multi Agent System Description}

During the phase of the parking tests, we noticed the presence of different elements, a non-linear system, heterogeneous data, different decisions to be taken according to the case, to be able to manage all these challenges and ensure a good functioning of the parking we thought of using artificial intelligence and more precisely the notion of agents. 
Over the years, several definitions have been given to agents, but a common point between these definitions is that the agent is an autonomous entity with skills of perception, communication, and action on its environment in order to achieve the goals assigned to it. These agents can form or integrate a group of agents, which is called a multi-agent system. In this system, tasks, resources, and intelligence are distributed; the goal assigned to the system can be achieved through communication between agents. These capabilities will allow us to have an extensible system which will be a good tool to add modules easily. Besides, when an agent integrates a system, it allows him to evolve without changing his internal structure, desires or beliefs.

As we defined before, agents are Autonomous entities with specific goals, therefore the goal is to being able to develop a system that brought together these entities, selfish and adaptable and that cooperate at the same time. During development, we must have a system that brings together different cooperative agents, communicating and jointly planning the actions to be taken without competition between them. In addition, agents try to maximize their gains and this can only be done with the development of their knowledge independently as they go along through cooperation rather than competition. The authors [7] also confirm that multi-agent systems are based on the notion of cooperation, which distinguishes them from other disciplines such as expert systems.

To successfully carry out the cooperation mission, agents must be able to exchange their shared objectives, strategy and plan in order to successfully carry out their mission. Agents must communicate because if they do not communicate, it will be more appropriate to break down the tasks in such a way that it is independent, and can be carried out just by an agent [8]. Indeed, agents need a unified language that allows them to communicate with each other and with their environment, if an agent was faced with solving a problem for which he does not have the necessary knowledge, or if he has incomplete plans, it may be possible to solve the problem by communicating with his environment. To ensure exchange between agents, several approaches have been used from Remote Procedure Call (RPC) or Remote Method Invocation (RMI), to CORBA and Object Request Brokers (ORB's), but Foundation for Intelligent Physical Agent Agent Communication Language FIPA-ACL, the language we have decided to work with, remains the best because it does not only deal with simple objects, and does not describe states as a procedure or method but rather in a declarative language [9], in addition FIPA will allow us to specify how each agent will interact with its environment without touching the agent's internal architecture, which will expand the agent's knowledge and learning domain while keeping its foundations.
At the entrance to the car park, we have installed different components: a barrier, display screens, an OCR camera, an RFID antenna, and a ticket terminal. To guarantee the autonomy and proper functioning of the entrance, we have developed and implemented different agents, in the rest of this paper, we will describe a scenario at the parking entrance to clearly identify the role of each agent. Fig. 1 shows the different blocks.

\section{B. Scenario}

When a person arrives at the entrance to the car park, the entry agent must decide whether to initiate the entry process, this decision will depend on the information shared by the control agent about the available spaces, or the reservations made.

Suppose that there are places available, two tasks are triggered in parallel (1) capture of the license plate, and (2) identification of the driver. (1) This is done using the OCR camera, the plate is then sent to the entry agent for verification. For (2) the RFID agent identifies whether the driver at the entrance is a customer or a simple visitor, if he is a customer, the agent determines if his balance is critical, or he has problems with his subscription, so he shares messages with the display agent to inform the driver. The entry agent also sends messages about the customer to preference Agent, who is responsible for identifying the customer's preferences (person with reduced mobility, with an electric car, etc.), as stated by the history of use. If the driver is not a customer, then he must take a ticket, the ticket number is then sent to the entry agent.

After these two processes (identification and registration of license plate), the entry agent, in cooperation with the control agent, authorizes entry, in parallel the preferred agent chooses the best place to be assigned to him so that the display agent takes care of guidance through the screens in the middle of the car park. Table I resumes the description of each agent, his wishes and his triggers.

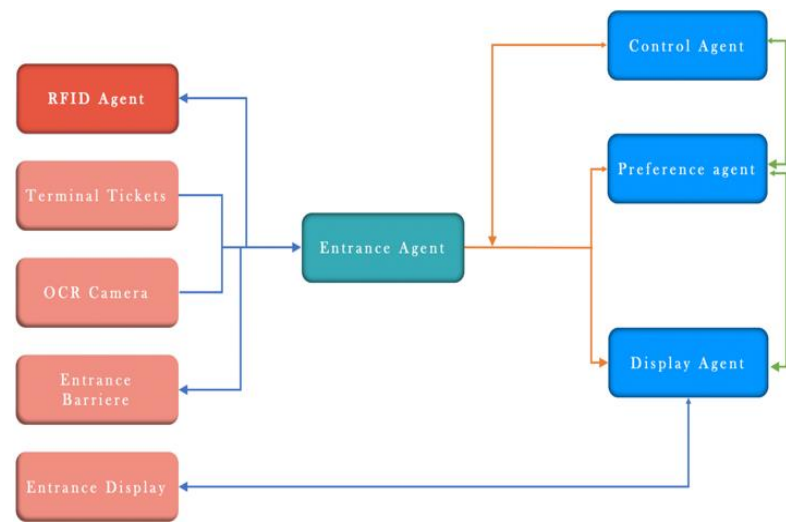

Fig. 1. The Agents in Charge of Entrance Management. 
TABLE I. AGENTS DESCRIPTIVE

\begin{tabular}{|c|c|c|c|}
\hline Agent & Description & Desire & Trigger \\
\hline RFID Agent & $\begin{array}{l}\text { Agent responsible for } \\
\text { identifying the type of } \\
\text { driver and the car, and } \\
\text { verifying the validity } \\
\text { of the subscription if it } \\
\text { is a customer. }\end{array}$ & $\begin{array}{l}\text { manage drivers } \\
\text { at the entrance } \\
\text { properly. }\end{array}$ & $\begin{array}{l}\text { Message from } \\
\text { the RFID or } \\
\text { ticket terminal }\end{array}$ \\
\hline $\begin{array}{l}\text { Entrace } \\
\text { Agent }\end{array}$ & $\begin{array}{l}\text { Agent responsible for } \\
\text { entrance management, } \\
\text { he is the middleman } \\
\text { between the parking } \\
\text { area and the entrance }\end{array}$ & $\begin{array}{l}\text { Avoid queues } \\
\text { at the entry } \\
\text { level } \\
\text { Manage entries }\end{array}$ & $\begin{array}{l}\text { Message } \\
\text { received from } \\
\text { the RFID } \\
\text { agent, or } \\
\text { control agent }\end{array}$ \\
\hline $\begin{array}{l}\text { Control } \\
\text { Agent }\end{array}$ & $\begin{array}{l}\text { Agent that is in } \\
\text { communication with all } \\
\text { system agents. } \\
\text { It determines, in } \\
\text { collaboration with the } \\
\text { entry and preference } \\
\text { agents, the most } \\
\text { appropriate location } \\
\text { and then communicate } \\
\text { it to the display agent. }\end{array}$ & $\begin{array}{l}\text { Minimize } \\
\text { anomalies }\end{array}$ & $\begin{array}{l}\text { Messages from } \\
\text { the other agent }\end{array}$ \\
\hline $\begin{array}{l}\text { Display } \\
\text { Agent }\end{array}$ & $\begin{array}{l}\text { he is in charge of } \\
\text { ensuring } \\
\text { communication with } \\
\text { drivers through screens } \\
\text { implemented at } \\
\text { different levels of the } \\
\text { car park. he must } \\
\text { determine which } \\
\text { message to display } \\
\text { (depending on the } \\
\text { product cases) and on } \\
\text { which screen (those at } \\
\text { the entrance, exit...) }\end{array}$ & $\begin{array}{l}\text { Transmit the } \\
\text { message } \\
\text { correctly to } \\
\text { drivers. }\end{array}$ & $\begin{array}{l}\text { Messages from } \\
\text { the other agent }\end{array}$ \\
\hline $\begin{array}{l}\text { Preference } \\
\text { Agent }\end{array}$ & $\begin{array}{l}\text { Determines customer } \\
\text { preferences based on } \\
\text { their usage history. }\end{array}$ & $\begin{array}{l}\text { Satisfying } \\
\text { customers }\end{array}$ & $\begin{array}{l}\text { Message from } \\
\text { the entry agent }\end{array}$ \\
\hline
\end{tabular}

\section{PARKING WAiting LinE}

When developing a solution for managing entry, we found that we need to do a study of the queue.

Indeed, the car park is an entity offering services to drivers, by offering these services the phenomenon of queuing can occur either at the entrance or exit. Queue modeling will allow us to test the performance of our system and its ability to manage requests while respecting real time constraints, and find a solution to this phenomenon (Fig. 2).

The service at the entrance follows a First In First Out (FIFO) model, In order to model the queue, we will assume that the arrival of the cars follows a stochastic model such that all events are independent, i.e. the arrival of the Vi car does not depend on the arrival of the Vi+1 car or Vi-1. In addition, it is also assumed that the arrivals follow a parameter fish law and the number of drivers admitted follows an exponential parameter law.

According to Kendal's notation our system follows the following model: $\mathrm{M} / \mathrm{M} / 1 /$ or:
- M: represents the Markovian law associated with arrivals.

- M: represents the Markovian law associated with departures.

- 1: Represents the number of servers (for our case we have only one server)

- represents the length of the tail, which is infinite for our case

For our system we assume that the length of the tail is infinite, therefore we must make sure that the fraction / must be less than 1 because otherwise (i.e. / $>1$ ), the length of the tail will increase and therefore people who will join the system after may not be served.

On the other hand, during the waiting period, two phenomena can occur.

Balking: when a driver arrives at the entrance but decides to leave without joining the queue, this departure can be forced either if there is no more space available (forced balking) or he estimates that the waiting time will be long for him don he decides to leave (unforced balking)

Reneging: when a driver joins the queue, so he automatically joins the system, but decides to leave halfway.

Our system has no memory, so it has memory less, i. e. during a very small interval only one event can occur, whether it is an arrival or a service.

From this hypothesis, we can deduce that in a time $(\mathrm{t}+\mathrm{h})$ only the following events can occur:

- 1 arrival 0 Service

- 0 Arrival 1 service

- 0 Arrival and 0 services

Based on these assumptions, we can deduce the probability $P_{n}$ : the probability in the stable state $u$ system that there is $n$ person in the system is written as follows:

$(\lambda+\mu) P_{n}=\lambda P_{n-1}+\mu P_{n+1}$

Based on the basic conditions and events that may occur, we find that $\mathrm{P}_{0}$ and $\mathrm{P}_{1}$ are linked by the following formula:

$\mu P_{1}=\lambda P_{0}$

So for $n=1$ and replacing equation (1) by the value of equation (2) we find:
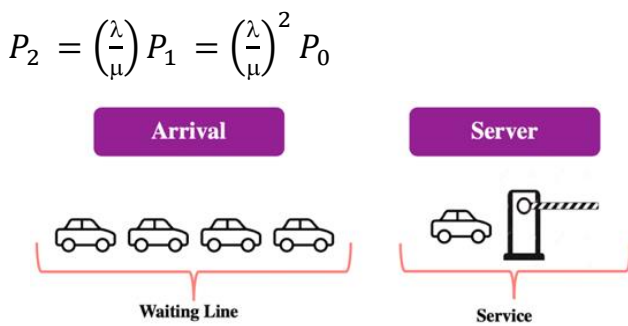

Departure

Fig. 2. Queue Model.

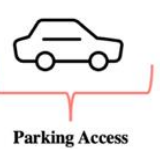

Parking Access 
So :

$P_{n}=\left(\frac{\lambda}{\mu}\right)^{n} P_{0}$

On the other hand,

$\sum_{i=1}^{\infty} P_{i}=1$

We have $\frac{\lambda}{\mu}<1$, so applying the formula of the geometric sequence we have.

$P_{O}+P_{1}+P_{2}+\cdots \infty=1$

According to (3) :

$P_{0}+\rho P_{0}+\rho^{2} P_{0}+\cdots \infty=1$

$P_{0}\left(\frac{1}{1-\rho}\right)=1$

$P_{0}=1-\rho$

Knowing that $\rho=\frac{\lambda}{\mu}$

So the probability $\mathrm{P}_{\mathrm{n}}$ can be written as follows:

$P_{n}=\rho^{n}(1-\rho)$

On the other hand, for a good management of the parking we must be interested in 4 parameters:

- Length of the system Ls: excepted number of persons who are at the system including the person who is being served

$L_{s}=\frac{\rho}{1-\rho}$

- Queue length Lq: expected number of people waited for service

$L_{q}=L_{s}-\rho$

- Waiting time in the system Ws.

$W_{s}=\frac{L_{s}}{\lambda}$

- Waiting time in the queue Wq.

$W_{q}=\frac{L_{q}}{\lambda}$
These parameters depend on the probability of the existence of $n$ people in the system.

\section{CONCLUSION}

In this paper, we have focused on the management of entry through an intelligent parking system from a decision-makers viewpoint and collaboration between agents. As well as considering existing research that discusses the phenomenon of the parking queue. In this paper we have used the theory i.e. the model and queue equations to carry out a simulation of the model using data collected from the real car park for study, aiming to improve the communication and collaboration algorithms between the agents of the system.

\section{REFERENCES}

[1] M. Lom, and O. Pribyl, and I. N. Sneddon, "modeling of smart city building blocks using multi-agent systems," Neural Network World 27(4):317-331 · January 2017.

[2] K. Farkas, and I. Lendák "Simulation Environment for Investigating Crowd-sensing Based Urban Parking," 2015 Models and Technologies for Intelligent Transportation Systems (MT-ITS), 3-5. June 2015. Budapest, Hungary.

[3] M. Bilal, C. Persson, F. Ramparany, G. Picard, and O. Boissier, "MultiAgent based governance model for Machine-to-Machine networks in a smart parking management system" 2012 IEEE International Conference on Communications (ICC), 10-15 June 2012, in Ottawa, ON, Canda.

[4] I. Benenson, K. Martens, and S. Birfir, "PARKAGENT: An agent-based model of parking in the city," Computers, Environment and Urban Systems, Volume 32, Issue 6, November 2008, Pages 431-439.

[5] S. Y. Chou, S. W. Lin , and C. C. Li, "Dynamic parking negotiation and guidance using an agent-based" platform Expert Systems with Applications Volume 35, Issue 3, October 2008, Pages 805-817.

[6] S. Benhassine, R. Harizi , and R. Mraïhi, "Intelligent Parking Management System by Multi-Agent Approach: The case of Urban Area of Tunis" 2014 International Conference on Advanced Logistics and Transport (ICALT), Hammamet, Tunisia, 1-3 May 2014.

[7] J. E. Doran, S. Franklin, N. R. Jennings, And T. J. Norman "On Cooperation In Multi-Agent Systems" The Knowledge Engineering Review Volume 12, Issue 3, pp. 309-314, September 1997.

[8] L. Panait, and S. Luke "Cooperative Multi-Agent Learning: The State of the Art" Autonomous Agents and Multi-Agent Systems, Volume 11, Issue 3, pp 387-434, November 2005.

[9] Y. Labrou, T. Finin, and Yun Peng "Agent communication languages: the current landscape" IEEE Intelligent Systems and their Applications, Volume: 14 , Issue: 2 , Mar/Apr 1999. 